\title{
Article
}

\section{French-English bilingual children's motion event communication shows crosslinguistic influence in speech but not gesture}

Miller, Nadia, Furman, Reyhan and Nicoladis, Elena

Available at http://clok.uclan.ac.uk/22798/

Miller, Nadia, Furman, Reyhan ORCID: 0000-0001-6034-3820 and Nicoladis, Elena (2018) French-English bilingual children's motion event communication shows crosslinguistic influence in speech but not gesture. Language, Interaction and Acquisition, 9 (1). pp. 69-100. ISSN 1879-7865

It is advisable to refer to the publisher's version if you intend to cite from the work. http://dx.doi.org/10.1075/lia.15006.mil

For more information about UCLan's research in this area go to http://www.uclan.ac.uk/researchgroups/ and search for <name of research Group>.

For information about Research generally at UCLan please go to http://www.uclan.ac.uk/research/

All outputs in CLoK are protected by Intellectual Property Rights law, including Copyright law. Copyright, IPR and Moral Rights for the works on this site are retained by the individual authors and/or other copyright owners. Terms and conditions for use of this material are defined in the policies page. 
French-English bilingual children's motion event communication shows cross-linguistic influence in speech but not gesture

Nadia Miller, Reyhan Furman, \& Elena Nicoladis

University of Alberta 


\begin{abstract}
Bilinguals sometimes show influence from one language while speaking (or gesturing) the other, or cross-linguistic influence. Adult bilinguals have also shown crosslinguistic influence in gestures as well as speech, suggesting an underlying conceptualization that is similar for both languages. The primary purpose of the present study was to test if the same is true of simultaneous French-English bilingual children in speaking and gesturing about motion. If so, they might show different patterns from both French and English monolinguals. Secondarily, we examined whether there were developmental changes between early and middle childhood. French-English bilingual and French and English monolingual children watched two cartoons and described them. In speech, the bilinguals differed from the English monolinguals, using more lexicalizations of the path of motion in token numbers but not in type. They did not differ from the French monolinguals. In gestures, all the children used a majority of path gestures. There were few age-related changes. We argue that in speech the bilinguals conceptualize their two languages differently, but show some cross-linguistic influence due to processing. Gestures may not show this same pattern because they serve to highlight the important parts of the discourse.
\end{abstract}




\section{Bilingualism impacts language usage and representation}

Bilingual children can differentiate their languages starting early in development, both in terms of context of use (Genesee, Boivin, \& Nicoladis, 1996; Genesee, Nicoladis, \& Paradis, 1995) and in terms of syntactic structure (Paradis \& Genesee, 1996). Nevertheless, bilinguals do not necessarily use both of their languages like monolinguals of either language. For instance, bilingual children show differences from monolinguals in acquisition, such as lags in development in some areas of language (Nicoladis \& Marchak, 2011; Nicoladis, Palmer, \& Marentette, 2007; Nicoladis, Song, \& Marentette, 2012; see review in Nicoladis, 2008). Bilinguals sometimes show cross-linguistic influence, or evidence of linguistic constructions and/or frequency of usage that is influenced by the other language (Hendricks, Hickmann, \& Demagny, 2008; Jarvis \& Pavlenko, 2008; Müller \& Hulk, 2001; Nicoladis, 2012; Paradis \& Navarro, 2003). For example, Paradis and Navarro (2003) showed that a Spanish-English bilingual child used more overt pronouns in Spanish than monolingual children, perhaps in part because even though Spanish allows pronoun-dropping English does not. Similarly, Nicoladis (2012) showed that French-English bilinguals used more periphrastic possessive constructions in English (e.g., the hat of the dog) than English monolinguals, suggesting influence from the periphrastic construction in French.

It is clear that cross-linguistic influence does not indicate that bilingual children have confused the two languages (Nicoladis, 2016). For example, in most studies on cross-linguistic influence in simultaneous bilingual children, the observed rate has been low, accounting for less than half of what bilinguals produce (Nicoladis, 2012; 2006; Nicoladis \& Gavrilla, 2015). What, then, is the source of cross-linguistic influence? Some 
researchers have argued that cross-linguistic influence is the result of representation of two languages interfacing with some other domain of language, such as pragmatics (Müller \& Hulk, 2001) or semantics (Liceras, Fuertes, \& de la Fuente, 2012). Other researchers have argued that cross-linguistic influence results from a shared conceptual structure underlying both languages (Jarvis \& Pavlenko, 2008). Alternatively, crosslinguistic influence could come from processing demands (Nicoladis, 2012; 2006). We discuss these alternative approaches to explaining cross-linguistic influence in more detail below in order to make predictions for the present study.

In the present study, we examine whether bilingual children between 5 and 10 years of age show cross-linguistic influence in speaking and gesturing about motion events. Specifically, we investigate how children who are bilingual in typologically different languages, English and French, talk and gesture about motion events and compare them to their monolingual counterparts. While English and French are generally considered typologically different languages, they also share some aspects of the underlying conceptualization of motion events. This similarity could be conducive to cross-linguistic influence appearing in bilingual children's speech and gestures.

\subsection{Cross-linguistic Differences in the Expression of Motion Events}

Motion events are events during which a figure moves in space from one location to another. Languages differ in how they map the semantic components of a motion event into lexical units and syntactical structures (Slobin, 1987; Talmy, 1985, 2000). Satelliteframed languages, such as English, typically encode manner in the main verb and path in a satellite, as in (1). In contrast, verb-framed languages, such as French, often express path in the main verbs and optionally encode manner in a subordinate verb, as shown in 
(2). These differences in lexicalization influence the choice of main verbs and also how semantic elements are syntactically packaged, with satellite-framed languages encoding manner and path in a single clause, as in (1) and verb-framed ones expressing them in separate clauses, as in (2).

(1) Pink Panther flies down.

(2) La panthère rose descend en volant.

Pink Panther descends by flying

Speakers can also encode motion events in their gestures, hand movements expressing the path and/or manner of movement (Kita \& Özyürek, 2003; McNeill, 1992; Stam, 2006). To express path, speakers can use a finger or a hand to trace the trajectory of motion from one location in gesture space to another. To express manner, speakers can use their hands in a variety of ways to represent how a figure moves (e.g., for flying, speakers might flap their arms next to their sides like bird wings). Manner and path can be conflated in gestures when the hands are used to represent both simultaneously. While the meaning of co-speech gestures often complements the meaning of the speech among adults (McNeill, 1992), gestures encoding motion sometimes do not, as will become clearer in the following discussion.

\subsubsection{Monolinguals}

Typological differences exist in the type and token frequency of the verbs that monolinguals use when they talk about motion. Speakers of satellite-framed languages, 
like English, tend to use a larger number and variety of manner verbs (e.g. roll, spin, bounce) compared to speakers of verb-framed languages such as French, who in turn frequently use path verbs (e.g. traverser 'to cross', monter/descendre 'to ascend/descend') in their motion event descriptions (e.g. Choi \& Bowerman, 1991English vs. Korean; Gullberg, Hendricks \& Hickmann, 2008- French; Hickmann, Taranne \& Bonnet, 2009- English vs. French; Ochsenbauer, 2010- German vs. French; Özçalışkan \& Slobin, 1999- English vs. Spanish and Turkish; McNeill, 2000; Naigles, Eisenberg, Kako, Highter \& McGraw, 1998- English vs. Spanish; Papafragou, Massey \& Gleitman, 2002, 2006- English vs. Greek).

As for gestures, monolinguals often produce gestures that reflect the typical lexicalization patterns observed in speech. For example, English monolinguals often produce manner of motion conflated with path (e.g., a gesture that simultaneously conveys both 'rolling' and a downward motion while speaking about 'rolling down'; Brown \& Gullberg, 2008). Speakers of verb-framed languages like Turkish and Japanese often produce separate gestures for path and manner, corresponding to the separate units in speech (Brown \& Gullberg, 2008; Kita \& Özyürek, 2003; Özyürek et al., 2005, 2008).

However, it is not always the case that gesture use reflects motion event typology. One study showed that English monolingual adults often gestured about path-only while their speech conflated manner and path (Hickmann, Hendricks, \& Gullberg, 2011). In other words, their gestures tended to emphasize the path while their speech also included manner. The authors concluded that English speakers have the possibility of choosing to gesture to highlight the path of motion if they wish.

\subsubsection{Bilinguals}


Previous research on motion event encoding has predominantly focused on monolingual speakers. There are, however, some studies that investigated how bilingual speakers talk about motion events in their different languages. Hohenstein, Eisenberg, and Naigles (2006) examined highly fluent bilinguals who spoke Spanish (verb-framed) and English (satellite-framed), and contrasted their motion event descriptions to those of monolinguals. Interestingly, bilinguals exhibited a pattern that was in between the two monolingual groups. That is, they used more manner verbs in Spanish than monolinguals and more path verbs in English than monolinguals (see also Filipovic, 2011). This convergence in word choice across languages suggest that the bilinguals were showing signs of cross-linguistic influence in both languages.

Daller, Treffers-Daller, and Furman (2011) also reported cross-linguistic influence in German-Turkish bilinguals' motion lexicalization. This study included two groups of bilinguals: one who resided in Turkey and the other in Germany. The researchers observed that the direction of cross-linguistic influence was different for the two groups of bilinguals. The bilinguals who resided in Turkey tended to use more verbframed constructions (i.e., like Turkish) in both their languages and those who resided in Germany tended to use more satellite-framed constructions (i.e., like German) in both their languages. The authors suggested that language dominance might be related to the directionality of cross-linguistic influence.

Similar patterns of L1-L2 convergence have also been documented for bilinguals at intermediate levels of L2 proficiency (Stam, 2006). In two recent studies, Brown and Gullberg $(2013,2012)$ examined bilinguals with an L1 of Japanese (verb-framed) and an L2 of English (satellite-framed). Bilinguals were found to use multiple clauses to encode 
manner and path more frequently than monolingual speakers of these languages. The authors argue that bilinguals' tendency to use multiple clauses might be caused by their acquisition of, and increased exposure to English. Other studies have documented that Japanese-English bilinguals differ from monolingual speakers of both languages in their frequency of encoding manner (Brown \& Gullberg, 2008) and path (Brown \& Gullberg, 2010), both in gesture and in speech. Specifically, whereas the bilinguals used more manner and less path in Japanese than Japanese monolinguals, they also used less manner and more path than English monolinguals. They were thus using patterns of motion lexicalization in between the monolingual patterns documented for English and Japanese.

Adults with a satellite-framed L1 (English or Russian) learning a verb-framed L2 (French or Spanish) have shown little to no signs of cross-linguistic influence (cf. Cadierno \& Ruiz, 2006). L1 English learners of L2 French have been found to use mainly path verbs in their motion event descriptions in French, unlike English monolinguals who tend to use manner verbs (Soroli, Sahraoui, \& Sacchet, 2012). Similarly, L1 Russian learners of L2 French also used many path verbs in describing motion, like native French speakers (Iakovleva \& Hickmann, 2012). Navarro and Nicoladis (2005) reported similar results with the Spanish of L1 English speakers with advanced proficiency in L2 Spanish. In sum, bilingual adults often show evidence of cross-linguistic influence in encoding motion events from at least a level of intermediate proficiency in their L2, in both speech and gesture. This cross-linguistic influence has generally been bidirectional, that is, differs from patterns of usage between monolinguals in both languages and converges across languages. One exception is adults who speak a satellite-framed language as their L1: they do not necessarily show cross-linguistic influence in their L2 
verb-framed language. Most previous studies of bilinguals have focused on late second language acquisition. As the bilingual children in our study are simultaneous bilinguals, it is important to understand the development of motion event expressions in childhood.

\subsection{Development of Motion Event Expressions in Children}

\subsubsection{Monolinguals}

Children learning satellite-framed languages like English sometimes use words encoding path among their earliest words (Berman \& Slobin, 1994). As children's language complexity increases, they tend to encode path (in satellites) quite early, often with light verb of motion (like 'go out') (Berman \& Slobin, 1994; Nicoladis \& Yin, 2010). These kinds of findings have led some researchers to speculate that human infants are predisposed to attend to and therefore wish to talk about the path of movement (Mandler, 1996; Talmy, 1991).

The effects of the ambient language soon appear on children's language use. From as early as 17 months, English- and Korean-speaking children describe motion using the patterns expected of their satellite- and verb-framed languages, respectively (Choi \& Bowerman, 1991). Other studies have examined how slightly older children learn the different lexicalization patterns that encode the semantic elements of motion events. Oh (2003) found that both adult and 3-year-old English speakers used significantly more manner verbs in motion event descriptions, and significantly fewer path verbs, than their Korean counterparts. Similarly, Spanish- and Turkish-speaking 3year-olds (both verb-framed languages) have been found to use more path verbs when talking about motion, whereas English-speaking children use more manner verbs (Özçalışkan \& Slobin, 1999). Similar results have also been reported for children aged 4- 
12, and adults speaking English (satellite-framed) and Greek (verb-framed) (Papafragou, Massey, \& Gleitman, 2002) as well as German (satellite-framed) and French (verbframed) (Ochsenbauer, 2010).

Compared to speech, language specificity in the gestural representation of motion events has been found to develop later (Özyürek et al., 2008). English-speaking 3- and 5year olds use separate gestures for path and manner, similar to their Turkish-speaking peers and unlike English-speaking 9-year-olds and adults who conflate manner and path into a single gesture. In contrast, Turkish speakers of all ages use separate gestures for path and manner.

Finally, of particular interest to the present study, is how children speaking French (verb-framed) acquire the language-specific patterns of motion event expression compared to their peers who speak English (satellite-framed). Hickmann and colleagues have examined the early spontaneous productions between the ages of 2 and 4 (Hickmann, Hendriks, \& Champaud, 2008), as well as elicited descriptions from children aged 3 years and above and from adults (Hickmann, 2003, 2006, 2007; Hickmann \& Hendriks, 2006; Hickmann et al., 2011; Hickmann, Taranne \& Bonnet, 2009; Ochsenbauer, 2010). They found that young French children tended to talk about path more frequently than manner. Whenever they did talk about both manner and path, they produced utterances where they distributed each element to a different sentence (Il arrive au bord de la rivière, il plonge, il nage et il va jusqu'à l'autre côté 'He arrives at the river bank, he dives, he swims and he goes to the other side'). French adults, on the other hand, used descriptions that encoded manner and path in different verbal clauses (e.g. traverser en courant 'to cross by running'). Whereas French adults jointly encoded path and 
manner more frequently than children do, they still did so less frequently than English adults. English-speaking children, on the other hand, produced significantly more utterances conflating manner and path than their French-speaking peers, although did not do so as frequently as their English-speaking adult counterparts.

Hickmann et al. (2011) directly addressed the development of spoken and gestural encodings of motion in English and French monolinguals in 4-year olds, 6-year olds and adults. They found that English-speaking children coded more path-only in speech than adults, but all English monolinguals had a preference for encoding path-only in gestures. French monolinguals preferred speaking and gesturing about the path of movement.

In sum, monolingual children's earliest encoding of motion often highlights the path of motion, regardless of the typology of their input language. Children's speech rapidly takes on properties of the typology of their input language. Children's gestures can encode the properties relevant for the typology of their input language early on, although there is some evidence that this development in gestures is later than in speech. Of particular relevance for this study is the finding that English-speaking children can sometimes gesture about the path of motion, even when primarily speaking about manner (Hickmann et al., 2011).

\subsubsection{Bilinguals}

To date, very little is known about how bilingual children learning typologically different languages talk about motion. Only one study has examined the expression of motion in French-English bilingual children (Nicoladis \& Brisard, 2002). That study found that the children, who were between 3 and 5 years of age, mainly encoded path in both French and English, both in their speech and in their gestures. 
One possible interpretation of these results is that the bilingual children were showing cross-linguistic influence in motion encodings, focusing primarily on path in both languages. Another possible interpretation is that the children were showing a developmental lag in encoding motion. A lag would be apparent only in English, in which children show an early preponderance of encoding path and later manner (see discussion above). To distinguish between these two possibilities, it is necessary to study older bilingual children and compare their results to monolingual children in both languages.

\subsection{Conceptualization, Processing, and Cross-linguistic Influence}

Different models for language production and comprehension have been proposed (Jay, 2003). The present study is based on a production task so we focus here on how language and gesture production models might predict bilinguals' performance.

Production models often suggest that speakers might first conceptualize their message, then choose the words and grammatical constructions to convey that message (the lemma level), and finally produce the phonological and/or gestural form associated with the lemma level (Levelt, Roelofs, \& Meyer, 1999; Krauss, Chen, \& Gottesman, 2000).

Jarvis and Pavlenko (2008) have argued that bilinguals' cross-linguistic influence results from a shared conceptualization underlying both languages (see also Pavlenko, 2009). This argument would explain why bilinguals sometimes use different motion encodings (in both speech and gesture) from monolinguals of both languages (Brown \& Gullberg, 2010; 2008; Daller et al., 2011; Filipovic, 2011; Hohenstein et al., 2006; Stam, 2006). In the present study, we might observe that the French-English bilinguals use motion encodings in both speech and gestures in ways that differ from both French and 
English monolinguals. In French, the bilinguals might express manner of motion (either simply or conflated with path) more often than monolinguals. In English, the bilinguals might express path of motion more often than monolinguals.

In contrast, Nicoladis (2006) has argued that bilinguals' cross-linguistic influence in production results from competition at the lemma level. In support of this argument is research showing that cross-linguistic influence is generally observed when bilinguals' two languages share similar ways of conceptualizing the objects or events to be talked about (Nicoladis, 2012; 2006; Nicoladis \& Gavrila, 2015) rather than when the languages differ in the underlying conceptualization (Nicoladis, Rose, \& Foursha-Stevenson, 2010). In other words, when bilinguals must think differently to speak a particular language, no cross-linguistic influence is observed (Nicoladis et al., 2010). In contrast, when there is similarity in the conceptualization underlying the two languages, there would be competition between bilinguals' two languages and cross-linguistic influence would result.

Thus, in articulating possible predictions for this study, it is important to understand the degree of similarity in conceptualization between motion event lexicalizations in French and English. Motion events differences in French and English can be conceptualized more as a matter of degree than categorically (Hickmann, 2003, 2006, 2007; Hickmann \& Hendriks, 2006; Hickmann et al., 2011). For example, in French, manner verbs can be main verbs (e.g., elle marche dans la cuisine, literally 'she walks in the kitchen'; Gullberg et al., 2008) and path verbs can be main verbs in English (e.g., he descended the staircase). To the degree that monolinguals differ in conceptualizing motion events, bilinguals should also differ between their two languages 
and resemble monolinguals in the two respective languages. In the present study, the types of verbs and the gestures used to encode motion should reflect this pattern. The verb types reflect knowledge of the language rather than lexical access. Therefore, when speaking French, bilinguals should use more verb types and gestures to refer to path than in English and equivalently to French monolinguals. When speaking English, bilinguals should use more verb types and gestures to refer to manner of motion than in French and equivalently to English monolinguals.

Since there is some similarity in conceptualizing motion events for speaking French and English, there could be competition at the lemma level, resulting in some differences between bilinguals and monolinguals in the frequency of choosing words. In other words, while showing the above patterns with regard to verb types, bilinguals might show differences from monolinguals in terms of token numbers used to encode motion. Three possible outcomes with tokens might be predicted: 1) bidirectional cross-linguistic influence, 2) unidirectional influence from English, or 3) unidirectional influence from French. We briefly explain why each of these outcomes might be predicted.

Bidirectional cross-linguistic influence would mean that bilinguals differ from monolinguals in both of their languages, encoding more manner in French and more path in English than monolinguals (as in Hohenstein et al., 2006). If this result is found, then there is no way to decide whether explaining cross-linguistic influence at the conceptualization level (Jarvis \& Pavlenko, 2008) or the lemma level (Nicoladis, 2006) is more appropriate.

The bilinguals in the present study live in a part of Canada in which English is predominantly spoken. Previous research has shown that bilingual adults show cross- 
linguistic influence in the direction of the dominant language of the community (Daller et al., 2011). If that were the case here, then we might see that the bilinguals choose more satellite-framed constructions in French than monolinguals. The bilinguals might show little difference, if any, from monolinguals in English.

A third possibility is unidirectional influence of French on the bilinguals' English. To understand this prediction, it is important to recall that path encoding emerges earlier in English than manner encoding. Furthermore, recall that L1 speakers of satellite-framed languages learning a verb-framed L2 show little signs of cross-linguistic influence in their L2. Taken together, these results suggest that aspects of the verb-framed patterns of lexicalization might correspond to a simpler way to encode motion. If this were the case in the present study, the bilinguals might lexicalize path-only in English more often than monolinguals, but show no difference in French from monolinguals.

In sum, researchers do not agree whether cross-linguistic influence appears in the production of bilinguals because of shared conceptualization or because of competition at the lemma level. The present results could shed light on this debate, since the two explanations differ on predictions about verb types and gestures in encoding motion events. If the competition is at the level of shared conceptualization (Jarvis \& Pavlenko, 2008), then we should observe bidirectional cross-linguistic influence on verb types, verb tokens, and gestures. In contrast, if the competition is at the lemma level (Nicoladis, 2006), then we should observe bidirectional cross-linguistic influence on verb tokens and gestures but not on verb types.

\subsection{This study}


In the present study, we investigate how younger (5-6 years) and older (8-10 years) French-English bilingual children encode motion events in their speech and gesture, and compare them to their monolingual counterparts. We expected bilingual children to display some signs of cross-linguistic influence, as has been found with adult bilinguals (e.g. Hohenstein et al., 2006; Brown \& Gullberg, 2008; 2010). If the crosslinguistic influence is due to shared conceptualizations underlying both languages, the bilinguals should show little difference between languages and differences from French and English monolinguals in terms of their verb types, tokens of motion lexicalizations, and gestures. If cross-linguistic influence is due to competition at the lemma level, then bilinguals might show differences between their two languages in terms of verb types, as well as little difference from monolinguals on these measures. In contrast, their token number of motion lexicalizations and gestures might differ from monolinguals and show little difference between languages (i.e., show cross-linguistic influence).

Both speech and gesture were expected to reveal a similar pattern of results (as with adults; Brown \& Gullberg, 2008; 2010) since children's gestures have been found in some studies to encode the same information as their speech in the domain of motion event representation (Özyürek et al., 2008). Previous research has also found that children use gestures to supplement information missing from their speech either because they are too young to use fully-formed utterances (e.g. Özçalışkan \& Goldin-Meadow, 2005,2009 ), or because the language they speak allows them to omit arguments (e.g. Turkish: Demir, So, Özyürek, \& Goldin-Meadow, 2012; Furman, Küntay, \& Özyürek, 2014). However, we do not expect children's gestures to show a supplementary pattern in our study since they are old enough to represent crucial motion event components in 
speech. Recall that one exception to these findings was that English monolinguals have been observed to gesture about the path of motion even when the spoken lexicalizations have included manner (Hickmann et al., 2011). Thus, there is the possibility that English speakers choose to highlight the path of motion, a point we return to in the discussion.

\subsubsection{Confounding issues}

We also tested for three potentially confounding issues. First, there is an issue of dialect. To date, the results reported for French have been with continental French. The French-English bilingual children in this study spoke Canadian French. In Canada, French has been in contact with English for several centuries. Contact has been shown to affect motion lexicalizations, particularly in Romance languages (Munske, 1986). Thus, we wanted to verify that the monolinguals of Canadian French and English showed the same lexicalization patterns as had been reported previously with monolinguals of other dialects of French and English.

Second, bilinguals have often been reported to have smaller vocabulary sizes relative to monolinguals in both of their languages (see review in Smithson, Paradis, \& Nicoladis, 2014). As a result, when eliciting stories from bilinguals, they might display less variety in their word choice overall, resulting in less varied motion lexicalizations. To test for this possibility, we compared the total number of word types the children used to tell their stories. If the bilinguals used fewer word types than the monolinguals, this variable could be statistically controlled in the following analyses.

Third, a potentially confounding problem in the present study is rate of development. Bilingual children might not simply lag behind monolingual children in vocabulary size, but also in their development of motion encoding. If this were the case 
in the present study, this lag would detectable in English. The younger bilingual children might encode path more often than same-aged monolingual children in English. The older bilingual children would do so less often than the younger bilingual children and might not show any differences at all from the same-aged monolingual children.

It should be noted that some studies have found that the degree of language exposure (Hervé, Serratrice, \& Corley, 2016) and/or language dominance (Kupisch, 2007) is a predictor of cross-linguistic influence. However, not all studies have found similar results (see review in Nicoladis, 2016). For that reason, we did not systematically take exposure time into account in the present study.

\section{Methods}

\subsection{Participants}

The participants in this study were 22 French monolingual, 22 English monolingual, and 20 French-English bilingual children. To test for developmental effects, we divided the participants into two age groups: Younger (5-6 years old) and Older (8-10 years old). The background characteristics of the age/language groups are summarized in Table 1 . The monolingual participants did not receive any regular exposure to any other language than their native language, according to parental report. The English monolingual children were growing up in Edmonton, Alberta, Canada. The French monolingual children were growing up outside of Montreal, Quebec, Canada. The bilingual children were growing up in Edmonton. They had all heard both French and English since birth, most often from parents, although in one case a primary source of French was the grandparents who lived close by. The bilingual children were recruited through French language daycares, preschools or schools. According to the parents' reports, all the bilingual children were exposed to more French than English but the 
children themselves preferred to speak English. This pattern of exposure/usage has been observed in this area of Canada in previous studies (e.g., Paradis \& Nicoladis, 2007). Paradis and Nicoladis (2007) attribute this pattern to children's sensitivity to the fact that English is the majority language in Edmonton.

Insert Table 1 about here

\subsection{Materials and Procedure}

All participants watched two Pink Panther video clips. The first clip depicted the Pink Panther who was angry at a cuckoo clock and tries to drown him by throwing him over a bridge. He then feels guilty and goes back to save the bird, but the bird had already escaped and meets the Pink Panther back at home, and they become friends. In the second clip, the Pink Panther decides he wants to fly a plane and his flying goes terribly wrong, sending him on a trajectory into the atmosphere until he dives back into the city. The Pink Panther escapes from the jet and the excitement ends when he is safely on the ground. Two clips were used in order to provide enough opportunity for story telling and gesturing, as some children tell very short stories or may forget part of the stories. The video clips were approximately 8 minutes in total duration.

We identified the motion events in the two clips, totaling 56 events. The events included a variety of manners (e.g. climb, circle, roll, jump) and paths (e.g. around, down, up, through). 
The participants were video recorded as they retold the stories they saw in the video clips to an experimenter. Bilingual children completed this once in English and once in French, on separate days, which were counterbalanced by language. A native English speaker administered the English sessions and a native French speaker administered the French session.

\subsection{Coding}

\subsubsection{Word types in the narrative}

The number of different orthographic words each child used to tell the story was counted. This measure is referred to as word types and was an operationalization of children's vocabulary size. Nicoladis and Jiang (2015) showed that vocabulary scores are highly predictive of monolingual children's word types in a story-telling context.

\subsubsection{Coding speech for motion events}

Speech describing translational motion events was transcribed from the videos. The motion events depicting manner, path, or manner/path conflation were coded as such. See examples in Table 2. Note that in French path/manner conflation was coded when children used a main verb indicating manner (like voler 'to fly') and a preposition as a satellite (see Munske [1986] for similar constructions in other contact-forms of Romance languages). There were no instances of the children using a manner gerund in French. To increase reliability, the verbs the children used to lexicalize motion were classified as either path or manner verbs (relying on Cifuentes-Férez [2010] who classified English and Spanish verbs of motion; direct translations from French to 
Spanish were usually straightforward). See Appendix 1 for a complete list of the verbs the children used and how they were classified.

Insert Table 2 about here

The number of different path and manner verbs used by each child was counted. Since there were only two verb types, the dependent variable we used to measure verb type choice was the number of different path verbs out of the total number of different path and manner verbs, multiplied by 100 to make a percentage. The choice of path verbs in the numerator was arbitrary.

The token number of motion lexicalizations was the number of times a child used path-only, manner-only or path-manner conflations in telling the story. The existence of three possible categories posed an interesting challenge for the analyses that we address in section 2.4.

\subsubsection{Coding gesture for motion events}

All of the children's representational gestures with their hands were initially coded with the sound available to the coders. A representational gesture refers to a gesture that conveys through movement and/or shape and/or location something about the meaning of the speaker's message. In this study, we focus exclusively on the gestures that represented the path and/or manner of movement in the stroke and/or poststroke hold, following Hickmann et al. (2011). The stroke of a gesture is the part where meaning is represented, and where the most force is executed by the child's hand over the course of 
performing a gesture. The poststroke hold refers to a child holding his/her hand still momentarily. A path gesture was identified as a single smooth trajectory performed by the child's finger(s) or hand. A manner gesture was identified by some hand movement mimicking the manner of movement of the figure (such as an index and middle finger repeatedly moving back and forth to represent "running"). A conflated gesture encoded both of these attributes.

The gestures were then compared with the corresponding speech in terms of which aspects of motion were encoded in each modality. The speech was considered corresponding to the gesture if the child produced the stroke of the gesture within a word of a spoken motion construction that could be meaningfully connected to it. A complete overlap was identified if the speech and the gesture both encoded the same aspects of motion exhaustively. For example, if a child said, "He flew up", an overlapping gesture would have to include both flying (such as flapping the two hands like bird wings) and up (such as moving both hands up). For the gestures that did not show complete overlap, we analyzed the percentage of those that added or highlighted path. For example, if a child said, "He ran" and gestured the path of movement along a horizontal trajectory, that would be a gesture that added path. That same gesturing accompanying "He ran out of the city" would be a gesture that highlighted the path.

\subsubsection{Reliability of coding}

To check on the reliability of the coding, a second coder coded the motion lexicalizations and gestures from twenty sessions, with a total of 289 motion lexicalizations and 83 motion gestures. The second coder gave the same code to 268 (92.7\%) of the motion lexicalizations and $80(96.4 \%)$ of the motion gestures. All of the 
second coder's codings were in the direction of consistency with the categories listed in Appendix 1 so the second coder's codings were retained for the analyses.

\subsection{Analyses}

To analyze the children's motion encodings, we first compared the token and type number of motion lexicalizations and token number of motion gestures in a series of $2 \times 2$ [AgeGroup x LanguageGroup] ANOVAs. The means and standard deviations for these comparisons are summarized in Appendix 2. These analyses consistently showed main effects for AgeGroup, but few effects for LanguageGroup and no interactions. The main effects for AgeGroup mean that the younger children produced fewer motion encodings (both spoken and gestural) than the older children. For this reason, the main analyses rely on using percentages of different motion encodings (out of total number of motion encodings).

In comparing groups using percentages of motion encodings, we ran into the challenge that the path, manner, and path/manner conflations are not independent from each other. For this reason, we could not include all three in the same analyses of variance. To address this challenge, we first analyzed the children's percentage of path only, as percentages of the total number of motion lexicalizations in both tokens and types in speech. If they are showing the typical lexicalization patterns associated with each language, the French-speaking children should use more path-only than the Englishspeaking children. For speech, we then analyzed the percentage of simple manner out of all encodings using manner (i.e., manner only and path/manner conflated). The Englishspeaking children should use less simple manner than the French-speaking children. 
To analyze gestures, we first analyzed the percentage of path only gestures out of all gestures encoding motion. Here again, if the children follow the typical patterns of the languages, the French-speaking children should use more path only gestures than the English-speaking children. We did not analyze simple vs. conflated manner in gestures, as the children did not produce enough manner gestures to result in a reliable analysis (see below). We then analyzed the children's gestures in terms of the percentages of gestures with complete overlap with the aspects of motion encoded in the speech (e.g., path only gestures accompanying speech that only lexicalized path). We expected the language groups to mostly produce completely overlapping gestures; that is, the gestures would encode the same aspects of motion as their speech. As some previous studies have suggested that speakers of Romance languages encode manner in their gestures that is not lexicalized in their speech (McNeill \& Duncan, 2000), we thought it possible that the English-speaking children might use fewer gestures adding or highlighting path than the French-speaking children.

\section{Results}

\subsection{Total number of word types}

Table 3 summarizes the total number of word types used to tell the stories. For each language comparison, we performed a 2 x 2 [AgeGroup x LanguageGroup] ANOVA. For the monolinguals, there was a main effect for AgeGroup, $F(1,40)=22.05$, $\mathrm{p}<.001, \eta^{2}=.551$, but no main effect for LanguageGroup, $\mathrm{F}(1,40)=1.19, \mathrm{p}=.28, \eta^{2}=$ .030. The main effect for AgeGroup was due to the older children using more word types than the younger children. For the monolinguals, the interaction between AgeGroup and LanguageGroup was significant, $F(1,40)=10.62, p=.002, \eta^{2}=.265$. This interaction 
was likely due to there being little difference between the younger and older French monolinguals while there was a bigger difference between the younger and older English monolinguals. In French, comparing the monolinguals and bilinguals, there was a significant main effect for AgeGroup, $F(1,36)=9.55, p=.004, \eta^{2} p=.265$. The main effect for LanguageGroup, $\mathrm{F}<1$, and the interaction, $\mathrm{F}(1,36)=2.96, \mathrm{p}=.094, \eta_{\mathrm{p}}^{2}=$ .082 , did not reach significance. In English, comparing the bilinguals and monolinguals, there was a significant main effect of AgeGroup, $F(1,36)=29.08, p<.001, \eta^{2}{ }_{p}=.808$. Neither the main effect for LanguageGroup, $F(1,36)=1.45, p=.24, \eta^{2} p=.040$, nor the interaction, $\mathrm{F}(1,36)=1.96, \mathrm{p}=.17$, reached significance. For the bilinguals, the Language variable was included in the ANOVA as a repeated measure. The results showed that there was a significant difference between the two age groups, $\mathrm{F}(1,16)=$ 12.71, $p=.003, \eta_{p}^{2}=.795$. Neither the main effect for Language, $F<1$, nor the interaction, $\mathrm{F}<1$, was significant.

These results mean that the older children use more varied vocabulary than the younger children, but there was no difference between the bilinguals and the monolinguals in either language.

Insert Table 3 about here

\subsection{Lexicalization patterns in speech}

\subsubsection{Path types}


The dependent variable here was the percentage of path verb types out of path and manner verb types used by each child (see Table 3 for summary descriptive statistics; see Appendix 1 for the path and manner classifications). The monolinguals showed a main effect, for LanguageGroup, $F(1,40)=16.80, p<.001, \eta^{2} p=.296$, but no main effect for AgeGroup, $\mathrm{F}<1, \eta_{\mathrm{p}}^{2}=.001$, and no interaction, $\mathrm{F}<1, \eta_{\mathrm{p}}^{2}=.011$. The main effect for LanguageGroup was due to the French monolinguals using more path types $(\mathrm{M}=62.9 \%)$ than the English monolinguals $(\mathrm{M}=38.2 \%)$. In French, there were no differences between the monolinguals and the bilinguals by LanguageGroup, $F(1,38)=1.79, p=$ $.19, \eta_{\mathrm{p}}^{2}=.045$, AgeGroup, $\mathrm{F}<1, \eta_{\mathrm{p}}^{2}=.022$, or interaction, $\mathrm{F}(1,38)=1.80, \mathrm{p}=.19, \eta_{\mathrm{p}}^{2}$ $=.045$. In English, the bilinguals did not differ from the monolinguals by LanguageGroup, $\mathrm{F}(1,38)=1.18, \mathrm{p}=.28, \eta_{\mathrm{p}}^{2}=.030$, AgeGroup, $\mathrm{F}<1, \eta_{\mathrm{p}}^{2}=.001$, or interaction, $\mathrm{F}<1, \eta^{2} \mathrm{p}=.001$. The bilinguals showed a slightly higher percentage of path verb types in French than in English, but this difference did not reach significance, F (1, $18)=3.01, p=.10, \eta^{2}=.143$. There was no significant AgeGroup difference, $F(1,18)=$ 2.07, $\mathrm{p}=.17, \eta_{\mathrm{p}}^{2}=.103$, and no interaction, $\mathrm{F}<1, \eta_{\mathrm{p}}^{2}=.001$.

In sum, the French monolinguals used more path verb types than the English monolinguals, but the bilinguals did not differ from the monolinguals in either language.

\subsubsection{Path tokens}

The next set of analyses focused on the percentage of path only lexicalizations out of all motion lexicalizations in terms of token numbers. Table 3 summarizes the percentages of simple path lexicalizations out of all children's motion lexicalizations. We analyzed the data with $2 \times 2$ [AgeGroup $x$ LanguageGroup] ANOVAs. For the two monolingual groups, there was a significant main effect of LanguageGroup, $F(1,40)=$ 
5.63, $\mathrm{p}=.023, \eta^{2} \mathrm{p}=.123$, but no main effect for AgeGroup, $\mathrm{F}<1, \eta^{2} \mathrm{p}=.005$, and no interaction, $F(1,40)=1.37, p=.25, \eta_{p}^{2}=.033$. The effect of LanguageGroup was due to the French monolinguals using more path $(\mathrm{M}=63.5 \%)$ than the English monolinguals ( $\mathrm{M}=48.2 \%)$. In French, comparing the bilinguals and the monolinguals revealed no significant main effects: AgeGroup, $\mathrm{F}<1, \quad{ }_{\mathrm{p}}=.016$, LanguageGroup, $\mathrm{F}<1, \eta^{2} \mathrm{p}=.006$. There was, however, a significant interaction between AgeGroup and LanguageGroup, F $(1,38)=5.60, p=.023, \eta^{2} \mathrm{p}=.128$. As can be seen in Table 3 , this interaction is due to the older French monolinguals using less path than the younger children and the older bilinguals using more path in French than the younger bilinguals. In English, there was no significant difference by AgeGroup, $\mathrm{F}(1,38)=3.46, \mathrm{p}=.07, \eta^{2} \mathrm{p}=.084$, but there was a significant difference by LanguageGroup, $\mathrm{F}(1,38)=8.89, \mathrm{p}=.005, \eta^{2} \mathrm{p}=.190$. The interaction was not significant, $F(1,38)=1.02, p=.32, \eta^{2} \mathrm{p}=.026$. The main effect of languages was due to the bilinguals using more path $(\mathrm{M}=64.9 \%)$ than the monolinguals $(\mathrm{M}=48.2 \%)$. To compare the bilinguals' two languages, Language was included as a repeated measure in the ANOVA. There was no significant difference by Language, $F(1,18)=1.34, p=.26, \eta^{2}{ }^{2}=.069$. The main effect of AgeGroup was significant, $F(1,18)=7.47, \mathrm{p}=.014, \eta_{\mathrm{p}}^{2}=.293$. The interaction was not significant, $\mathrm{F}<$ $1, \eta_{\mathrm{p}}^{2}=.018$. The main effect of AgeGroup was due to the older children producing more path $(M=71.8 \%)$ than the younger children $(M=53.4 \%)$. In sum, these results showed that the French monolingual children used more path than the English monolingual children. The bilingual children used more path in English than the monolingual children and tended to use less path in French than the monolingual children (although only 
among the younger children). The bilinguals showed no difference between languages on this measure.

\subsubsection{Manner tokens}

We next turn to the analyses of the percentage of simple manner out of all lexicalizations including manner (see Table 3 for summary statistics). For the two monolingual groups, the main effect of LanguageGroup was significant, $F(1,40)=7.78$, $\mathrm{p}=.008, \eta_{\mathrm{p}}^{2}=.163$, as was the main effect for AgeGroup, $\mathrm{F}(1,40)=5.35, \mathrm{p}=.026, \eta^{2} \mathrm{p}$ $=.118$. The interaction was not significant, $\mathrm{F}<1, \eta_{\mathrm{p}}^{2}=.001$. The effect of LanguageGroup was due to the French monolinguals using more simple manner $(\mathrm{M}=$ $67.8 \%)$ than the English monolinguals $(\mathrm{M}=44.8 \%)$. The AgeGroup effect was due to the younger children producing more simple manner $(\mathrm{M}=65.8 \%)$ than the older children $(\mathrm{M}$ $=46.8 \%$ ). In French, there were no significant differences between the bilinguals and the monolinguals: AgeGroup, $\mathrm{F}(1,38)=2.07, \mathrm{p}=.16, \eta_{\mathrm{p}}^{2}=.052$, LanguageGroup, $\mathrm{F}<1$, $\eta_{\mathrm{p}}^{2}=.000$, and interaction, $\mathrm{F}<1, \eta_{\mathrm{p}}^{2}=.008$. In English, there was a significant difference by AgeGroup, $\mathrm{F}(1,38)=4.00, \mathrm{p}=.053, \eta_{\mathrm{p}}^{2}=.098$, but no significant difference by LanguageGroup, $F(1,38)=2.19, p=.25, \eta_{p}^{2}=.056$ and no interaction, $F$ $<1, \eta_{\mathrm{p}}^{2}=.001$. The main effect of AgeGroup was due to the younger children using more simple manner $(\mathrm{M}=59.6 \%)$ than the older children $(\mathrm{M}=42.6 \%)$. For the bilinguals, there were no significant differences: Language, $\mathrm{F}<1, \eta_{\mathrm{p}}^{2}=.054$, AgeGroup, $\mathrm{F}<1, \eta_{\mathrm{p}}^{2}=.032$, interaction, $\mathrm{F}<1, \eta_{\mathrm{p}}^{2}=.011$. In sum, these results show that the French monolinguals used more simple manner than the English monolinguals. The bilinguals did not differ from the monolinguals in either language (or between languages) in their use of simple manner. 


\subsection{Motion encoding in gestures}

Table 4 summarizes the children's use of motion gestures. As can be seen in this Table, the children had a very strong tendency to gesture about path, as evidenced by the Gesture \%Path. The monolinguals did not differ in their preference for path by LanguageGroup, $\mathrm{F}<1, \eta_{\mathrm{p}}^{2}=.030$. There was a significant difference by AgeGroup, $\mathrm{F}$ (1, $40)=4.32, p=.046, \eta^{2} p=.126$. The older children had a stronger preference for path (M $=94.4 \%)$ than the younger children $(\mathrm{M}=72.7 \%)$. There was no interaction between these variables, $F(1,40)=1.13, p=.30, \eta_{p}^{2}=.036$. In French, there was no difference by LanguageGroup, $\mathrm{F}<1, \eta_{\mathrm{p}}^{2}=.033$. The difference by AgeGroup did not reach significance, $F(1,38)=3.12, \mathrm{p}=.09, \eta_{\mathrm{p}}^{2}=.097$, although the older children tended to gesture more about path $(\mathrm{M}=93.3 \%)$ than the younger children $(\mathrm{M}=68.2 \%)$. The interaction was not significant, $F(1,38)=1.66, p=.21, \eta^{2} p=.054$. In English, there was no significant difference by LanguageGroup, $F(1,38)=1.47, p=.24, \eta^{2}=.052$, or AgeGroup, $\mathrm{F}(1,38)=1.11, \mathrm{p}=.30, \eta^{2} \mathrm{p}=.039$, and no interaction, $\mathrm{F}<1, \eta^{2} \mathrm{p}=.002$. For the bilinguals, there was no significant difference by Language, $F<1, \eta^{2} \mathrm{p}=.070$, AgeGroup, $\mathrm{F}<1, \eta_{\mathrm{p}}^{2}=.003$, or interaction, $\mathrm{F}<1, \eta_{\mathrm{p}}^{2}=.007$.

There were no significant differences by LanguageGroup or Language, AgeGroup, or interactions in terms of the percentage of gestures showing a complete overlap with the corresponding speech, all Fs $<1$. As can be seen in Table 4, the children produced a majority of gestures that completely overlapped with the motion components lexicalized in the corresponding speech.

As for the gestures with non-completely overlapping meaning, the children's gestures most often added or emphasized the path components, as can be seen in Table 4 . 
There were no significant differences between any Language Groups or Languages, Age Groups or interaction on this measure.

Insert Table 4 about here

In sum, these results show that among the monolinguals, the older children gestured more about path only than the younger children. The bilinguals did not differ from the monolinguals in either of their languages with regard to encoding path in gesture. The majority of children's gestures completely overlapped with the aspects of motion lexicalized in their speech, with no language or age differences. When the gestures did not completely overlap, the children added or highlighted the path of motion, with no language or age differences.

\section{Discussion}

In the present study, we compared French-English bilingual children's motion encodings in speech and gesture to those of monolinguals in order to shed light on the possible origins of cross-linguistic influence. As expected, we observed differences between the French and English monolinguals in directions predicted by the typology of their languages. The French monolinguals used more path verb types and used more pathonly lexicalizations than English monolinguals. The English monolinguals were more likely to conflate their manner lexicalizations with path, while French monolinguals were more likely to produce manner-only lexicalizations. 
Also, as expected, we did observe some signs of cross-linguistic influence among the bilinguals. In the next section, we explain how these findings might elucidate the processing origins of cross-linguistic influence.

\subsection{Bilinguals and cross-linguistic influence}

\subsubsection{Cross-linguistic influence and shared conceptualization}

One potential source of cross-linguistic influence in processing is a shared conceptualization for speaking both languages (Jarvis \& Pavlenko, 2008). If this were the case for the bilinguals in this study, we expected the bilinguals to use more satelliteframed-preferred patterns in their English and more verb-framed-preferred patterns in their French than monolinguals and little difference between their two languages.

Furthermore, this result would hold across verb types, tokens of lexicalization patterns, and gestures.

There were some findings consistent with these predictions. In terms of token numbers of lexicalizations, the bilinguals used less path (more manner) lexicalizations in French than the monolinguals, although only among the older children. In English, the bilinguals used more path than monolinguals (both age groups). And the bilinguals did not differ in their preference for path lexicalizations in their two languages.

However, the consistent results held only for the analyses of the token use. In terms of types, the bilinguals did not differ from either monolingual group in either language. We discuss the gesture results in section 4.2.

\subsubsection{Cross-linguistic influence and competition among lemmas}

These results are consistent with the proposal that cross-linguistic influence is due to competition between languages at the lemma level (Nicoladis, 2012; 2006; Nicoladis 
\& Gavrilla, 2015). The fact that the cross-linguistic influence in speech only shows up in terms of token frequency rather than type suggests that bilinguals might be using some of the same verbs (particularly path verbs) to express story events. While they can use just as many verb types reflecting path or manner as monolinguals of both languages, the task demands of telling a story might result in accessing verbs reflecting the other language typological pattern. Most previous studies showing cross-linguistic influence among bilingual adults have analyzed only tokens rather than types (e.g., Brown \& Gullberg, 2008; Hohenstein et al., 2006). Future research can test the generalizability of this finding to other bilingual groups.

In section 1.3, we considered three possible predictions in terms of how bilinguals might differ from monolinguals. The results corresponded with the third prediction considered in that section, namely, the cross-linguistic influence was observed only from French to English. This result is consistent with the explanation that bilinguals might have included more path-only lexicalizations in English than monolinguals because these lexicalizations are simpler for English speakers (i.e., developmentally earlier; Berman \& Slobin, 1994; Hickmann et al., 2011).

\subsubsection{Patterns inconsistent with both explanations}

The bilinguals did not differ from monolinguals in either language in their tendency to use either simple manner or manner conflated with path. One possible reason for this finding is the choice of elicitation material for this study. The difference between the two monolingual groups was fairly small so it is possible that this lack of difference does not so much reflect cross-linguistic influence, but an insensitive measure to how the children might lexicalize manner. Using stimuli in which manner of motion is more 
salient (such as in Allen et al., 2007) could have perhaps elicited more valid measures of manner.

\subsection{Gesture}

Up until now, we have discussed only the results with the participants' speech. The gesture results did not correspond to the results with speech. First, there were no differences between the monolinguals in their use of gestures to encode motion. Both the English and the French monolinguals produced a majority of gestures encoding path.

They mostly used gestures that corresponded with what they were saying; in other words, they mostly gestured about path when speaking primarily about path. When their gestures did not completely overlap with the motion variables encoded in speech, the monolinguals were mostly adding or emphasizing the path of motion. Thus, we found no cross-language difference in gesture encoding (cf. Brown \& Gullberg, 2008). Since we did not detect differences in gesture use between English and French monolinguals, it was not surprising that we found that the bilinguals did not differ from the monolinguals in either language in their gesture use.

These results replicate the findings among English and French monolinguals between 4 years old and adulthood in a previous study (Hickmann et al., 2011). Recall that in that study, both English and French monolinguals produced a lot of path gestures. This finding held true even for the English monolinguals when they included manner of motion in their speech. Furthermore, these results replicate those of French-English bilingual adults using the exact same elicitation material (Nicoladis \& Gynane, 2014). In that study, the adults, too, produced mostly path gestures and the gestures usually 
accompanied a motion lexicalization in which path was at least one component of the accompanying spoken lexicalization.

It is not clear why some studies find that gestures reflect the spoken typology of motion and others do not. One possible reason is, again, the method of elicitation. In this study, the cartoon that the children watched was largely concerned with the Pink Panther's movements from place to place. The children may have chosen to produce gestures in order to emphasize and/or remember the Pink Panther's movements to different locations. If this interpretation is correct, then children's reasons for producing gestures in a narrative context could include rhetorical or discursive functions. To test this possibility, future studies could include different elicitation tasks (e.g., a story emphasizing manner of movement vs. a story emphasizing moving from place to place) to see if children's gestures change according to story emphasis.

In sum, the children's gesture use did not show the same cross-linguistic differences observed in their speech, either for monolinguals or bilinguals. We have argued that the children may have been using gestures to emphasize the important events in the narrative.

\subsection{Potentially confounding issues}

In section 1.4.1, we mentioned three potentially confounding issues: language contact between French and English, bilinguals' vocabulary size, and bilinguals showing a lag in developing motion encodings relative to monolinguals. Here, we briefly discuss how these issues were unlikely to have affected the present results.

Canadian French has been in contact with Canadian English for centuries.

Previous studies have shown contact effects for motion lexicalizations (Munske, 1986). If 
there were little difference in the motion lexicalizations of monolingual French speakers and monolingual English speakers because of contact, there would be no possibility to test for cross-linguistic influence. However, we did show clear differences between monolingual French and English monolinguals, in the predicted directions. Thus, Canadian French has retained enough of a difference in lexicalizing motion from Canadian English that cross-linguistic influence could be detected.

Previous studies have shown that bilinguals often score lower on vocabulary tests than monolinguals (Smithson et al., 2014). If so, then bilinguals might produce fewer different word types than monolinguals in telling these stories simply because of smaller vocabularies. We compared the number of word types the children used to tell the story and found no significant differences between bilinguals and monolinguals. Thus, differences between bilinguals and monolinguals are unlikely to be due to differences in vocabulary size.

With the present data, we cannot entirely rule out the last potential confounding factor, the possibility that the bilinguals are showing a lag in development. Recall that young monolingual English-speaking children use a lot of path in talking about motion (Berman \& Slobin, 1994). So, the bilingual children might be delayed in developing talking about manner in English. There are several indications that this interpretation is unlikely. First, the older bilinguals used less path (i.e., more manner) encodings in their French than the monolinguals, so the cross-linguistic influence was observed in both languages. Second, the bilinguals used as many word types as the monolinguals in each of their languages to tell the story, suggesting that this group of bilinguals was not lagging behind the monolinguals in their overall lexical development. And finally, the 
bilinguals differed from the monolinguals only in terms of frequency measured in terms of tokens rather than types. This finding suggests that the bilinguals knew as many motion verbs as the monolinguals, but differed in their frequency of usage. Nevertheless, future studies also including independent measures of the children's language abilities in both languages would allow a more conclusive ruling out of the results being due to a developmental lag.

In sum, we have argued against the possibility that factors other than crosslinguistic influence are playing a role in bilingual children's productions.

\subsubsection{Limitations and Future Directions}

As noted earlier, we did not include quantitative measures of the children's exposure time to each language or their language dominance. Relative exposure time (Hervé et al., 2016) and/or dominance (Kupisch, 2007) have sometimes been found to predict cross-linguistic influence. Future studies could also include systematic measures

of exposure time and dominance. Similarly, we had no independent measures of withinlanguage proficiency (e.g., vocabulary tests in each language) for the children in this study. As noted in the last section, we cannot therefore be certain of whether the bilingual children were lagging in their development relative to monolingual children. Future studies that include measures of within-language proficiency can test for the possibility of a developmental lag with greater certainty.

Another limitation of this study was that our method of elicitation resulted in few gestures produced by the children. As we noted earlier, future studies can therefore include elicitation methods that result in greater gesture use.

\section{Conclusion}


In conclusion, we have shown that simultaneous French-English bilingual children's speech shows cross-linguistic influence when speaking about motion. As the cross-linguistic influence showed up in terms of token numbers rather than types of verbs, we have argued that these results are consistent with an explanation of crosslinguistic influence in terms of competition at the lemma level. In other words, the bilingual children show some signs of conceptualizing each of their languages like monolinguals (as shown by verb types), but show influence from the other language in their frequency of choosing motion lexicalization. The children's gesture use showed no evidence of cross-linguistic differences, either for the monolinguals or the bilinguals. These results could indicate that children's gestures did not simply reflect their conceptualization, but were chosen in order to highlight the important aspects of the story they were telling. 


\section{References}

Allen, S., Özyürek, A., Kita, S., Brown, A., Furman, R., Ishizuka, T., \& Fujii, M. (2007). Language-specific and universal influences in children's packaging of manner and path: A comparison of English, Japanese and Turkish. Cognition, 102, 1648.

Berman, R. A. \& Slobin, D. I. (1994). Relating events in narrative: A crosslinguistic developmental study. Hillsdale, NJ: Lawrence Erlbaum.

Brown \& Gullberg, M. (2013). L1-L2 convergence in clausal packaging in Japanese and English. Bilingualism: Language and Cognition, 16, 477-494.

Brown, A. \& Gullberg, M. (2012). Multicompetence and native speaker variation in clausal packaging in Japanese. Second Language Research, 28, 415-442.

Brown, A. \& Gullberg, M. (2010). Changes in encoding of PATH of motion in a first language during acquisition of a second language. Cognitive Linguistics, 21, 263-286.

Brown \& Gullberg, M. (2008). Bidirectional crosslinguistic influence in L1-L2 encoding of manner in speech and gesture: A study of Japanese speakers of English. Studies of Second Language Acquisition, 30, 225-251.

Cadierno, T., \& Ruiz, L. (2006). Motion events in Spanish L2 acquisition. Annual Review of Cognitive Linguistics, 4, 183-216.

Choi, S. \& Bowerman, M. 1991. Learning to express motion events in English and Korean: The influence of language-specific lexicalization patterns. Cognition, $41,83-121$. 
Cifuentes-Férez, P. (2010). The semantics of the English and the Spanish motion verb lexicons. Review of Cognitive Linguistics, 8, 233-271.

Daller, M., Treffers-Daller, J., \& Furman, R. (2011). Transfer of conceptualisation patterns in bilinguals: The construal of motion events in Turkish and German. Bilingualism: Language and Cognition, 14, 95-119.

Demir, Ö. E., So, W. C., Özyürek, A., \& Goldin-Meadow, S. (2012). Turkish-and English-speaking children display sensitivity to perceptual context in the referring expressions they produce in speech and gesture. Language and cognitive processes, 27, 844-867.

Filipovic, L. (2011). Speaking and remembering in one or two languages: Bilingual vs. monolingual lexicalization and memory for motion events. International Journal of Bilingualism, 15, 466-485.

Furman, R., Küntay, A., \& Özyürek, A. (2014). Early language-specificity of children's event encoding in speech and gesture: Evidence from caused motion in Turkish. Language, Cognition and Neuroscience, 29, 620-634.

Genesee, F., Boivin, I. \& Nicoladis, E. (1996). Bilingual children talking with monolingual adults: A study of bilingual communicative competence. Applied Psycholinguistics, 17, 427-442.

Genesee, F., Nicoladis, E., \& Paradis, J. (1995). Language differentiation in early bilingual development. Journal of Child Language, 22, 611-631.

Gullberg, M., Hendriks, H., \& Hickmann, M. (2008). Learning to talk and gesture about motion in French. First Language, 28, 200-236. 
Hendricks, H., Hickmann, M., \& Demagny, A.-C. (2008). How adult English learning of French express caused motion: A comparison with English and French natives. Acquisition et Interaction en Langue Etrangère, 27. Available: http://aile.revues.org/3973

Hervé, C., Serratrice, L., \& Corley, M. (2016). Dislocations in French-English bilingual children: An elicitation study. Bilingualism: Language and Cognition, 19(5), 987-1000.

Hickmann, M. (2003a). Children's discourse: person, space and time across languages. Cambridge: Cambridge University Press.

Hickmann, M. (2006). The relativity of motion in first language acquisition. In M. Hickmann \& S. Robert (Eds.), Space across languages: linguistic systems and cognitive categories (pp. 281-308). Amsterdam: John Benjamins.

Hickmann, M. (2007). Static and dynamic location in French: Developmental and crosslinguistic perspectives. In M. Aurnague, M. Hickmann, \& L. Vieu (Eds.), The categorization of spatial entities in language and cognition (pp. 205-231). Amsterdam: John Benjamins.

Hickmann, M., \& Hendriks, H. (2006). Static and dynamic location in French and in English. First Language, 26, 103-135.

Hickmann, M., Hendriks, H., \& Gullberg, M. (2011). Developmental perspectives on the expression of motion in speech and gesture: A comparison of French and English. Language, Interaction, and Acquisition, 2, 129-156. 
Hickmann, M., Taranne, P. \& Bonnet, P. (2009). Motion in first language acquisition: Manner and path in French and English child language. Journal of Child Language 36, 705-741.

Hohenstein, J., Eisenberg, A., \& Naigles, L. (2006). Is he floating across or crossing afloat? Cross-influence of L1 and L2 in Spanish-English bilingual adults. Bilingualism: Language and Cognition, 9, 249-261.

Iakovleva, T. \& Hickmann, M. (2012). Contraintes typologiques dans l'acquisition d'une langue étrangère: L'expression du mouvement chez les apprenants russophones du français. Langages, 4, 41-57.

Jarvis, S. \& Pavlenko, A. (2008). Crosslinguistic influence in language and cognition. New York: Routledge.

Jay, T. B. (2003). The psychology of language. Upper Saddle River, NJ: Prentice Hall. Kita, S., \& Özyürek, A. (2003). What does cross-linguistic variation in semantic coordination of speech and gesture reveal? Evidence for an interface representation of spatial thinking and speaking. Journal of Memory and Language, 48, 16-32.

Krauss, R. M., Chen, Y., \& Gottesman, R. F. (2000). Lexical gestures and lexical access: A process model. In D. McNeill (Ed.), Language and Gesture (pp. 261-283). New York: Cambridge University Press.

Kupisch, T. (2007). Determiners in German-Italian children: What they tell us about the relation between language influence and language dominance. Bilingualism: Language and Cognition, 10, 57-78. 
Levelt, W.J.M., Roelofs, A. \& Meyer, A.S. (1999). A theory of lexical access in speech production. Behavioral and Brain Sciences, 22, 1-75.

Liceras, J. M., Fuertes, R. F., \& de la Fuente, A. A. (2012). Overt subjects and copula omission in the Spanish and the English grammar of English-Spanish bilinguals: On the locus and directionality of interlinguistic influence. First Language, 32, 88-115.

Mandler, J. M. (1996). Preverbal representation and language. In P. Bloom, M. A. Peterson, L. Nadel \& M. F. Garrett (eds.), Language and space (pp. 365-384). Cambridge, MA: MIT Press.

McNeill, D. (1992). Hand and mind. Chicago: University of Chicago Press.

McNeill, D., \& Duncan, S. (2000). Growth points in thinking-for-speaking. In D. McNeill (Ed), Language and gesture (pp. 141-161). New York, NY: Cambridge University Press.

Müller, N. \& Hulk, A. (2001). Crosslinguistic influence in bilingual language acquisition: Italian and French as recipient languages. Bilingualism: Language and Cognition, 4, 1-21.

Munske, H. H. (1986). What are mixed languages? In P. H. Nelde, P. S. Ureland \& I. Clarkson (eds.), Language contact in Europe (pp. 81-95). Tübingen: Max Niemeyer Verlage.

Naigles, L. R., Eisenberg, A. R., Kako, E. T., Highter, M., \& McGraw, N. (1998) Speaking of motion: Verb use in English and Spanish. Language and Cognitive Processes, 13, 521-549. 
Navarro, S., \& Nicoladis, E. (2005). Describing motion events in adult L2 Spanish narratives. In Selected Proceedings of the 6th Conference on the Acquisition of Spanish and Portuguese as First and Second Languages (pp. 102-107).

Somerville, MA: Cascadilla Proceedings Project.

Nicoladis, E. (2016). Measuring language dominance in bilingual children:

Ramifications on predicting crosslinguistic influence. In C. Silva-Corvalán \& J. Treffers-Daller (Eds.) Operationalising and measuring language dominance (pp. 219-234). Cambridge: Cambridge University Press.

Nicoladis, E. (2012). Cross-linguistic influence in French-English bilingual children's possessive constructions. Bilingualism: Language and Cognition, 15, 320-328.

Nicoladis, E. (2008). Why does bilingualism affect language and cognitive development? In J. Altarriba \& R. Heredia (Eds.), An introduction to bilingualism: Principles and practices (pp. 167-181). Mahwah, NJ: Lawrence Erlbaum.

Nicoladis, E. (2006). Cross-linguistic transfer in adjective-noun strings by preschool bilingual children. Bilingualism: Language and Cognition, 9, 15-32.

Nicoladis, E., \& Brisard, F. (2002). Encoding motion in gestures and speech: Are there differences in bilingual children's French and English? In E. V. Clark (Ed.), Space In Language. Location, Motion, Path, and Manner. The Proceedings of the 31st Stanford Child Language Research Forum (pp. 60-68). Stanford: CSLI Publications.

Nicoladis, E. \& Gavrila, A. (2015). Cross-linguistic influence in Welsh-English bilingual children's adjectival constructions. Journal of Child Language, 42, 903-916. 
Nicoladis, E. \& Gynane, H. (2014). French-English bilinguals' motion encoding in speech and in gestures. Unpublished manuscript. University of Alberta.

Nicoladis, E. \& Jiang, Z. (2015). Language and cognitive predictors of lexical selection in storytelling for monolingual and sequential bilingual children. Unpublished paper. University of Alberta.

Nicoladis, E. \& Marchak, K. (2011). Le carte blanc or la carte blanche? Bilingual children's acquisition of French adjective agreement. Language Learning, 61, 734-758.

Nicoladis, E., Palmer, A. \& Marentette, P. (2007). The role of type and token frequency in using past tense morphemes correctly. Developmental Science, 10, 237-254.

Nicoladis, E., Pika, S., \& Marentette, P. (2009). Do French-English bilingual children gesture more than monolingual children? Journal of Psycholinguistic Research, $38,573-585$.

Nicoladis, E., Rose, A., \& Foursha-Stevenson, C. (2010). Talking for speaking and crosslinguistic transfer in preschool bilingual children. International Journal of Bilingual Education and Bilingualism, 13, 345-370.

Nicoladis, E., Song, J., \& Marentette, P. (2012). Do young bilinguals acquire past tense morphology like monolinguals, only later? Evidence from French-English and Chinese-English bilinguals. Applied Psycholinguistics, 33, 457-479.

Nicoladis, E. \& Yin, H. (2010). Evidence for the role of frequency in the acquisition of lexicalization patterns of Chinese-English bilingual children. Journal of Chinese Linguistics, 38, 288-322. 
Ochsenbauer, A.K. (2010). The impact of language-specific factors in first language acquisition: The expression of motion in French and German (Unpublished doctoral dissertation). Universite Paris 8, Paris France.

Özçalışkan, Ş. \& Slobin, D. I. (1999). Learning how to search for the frog: Expression of manner of motion in English, Spanish, and Turkish. In Proceedings of the 23rd Annual BostonUniversity Conference on Language Development: Vol. 2, A. Greenhill, H. Littlefield \& C. Tano (eds.), 163-174. Somerville, MA: Cascadilla Press.

Özçalışkan, Ş., \& Goldin-Meadow, S. (2005). Gesture is at the cutting edge of early language development. Cognition, 96, B101-B113.

Özçalışkan, Ş., \& Goldin-Meadow, S. (2009). When gesture-speech combinations do and do not index linguistic change. Language and Cognitive Processes, 24, 190-217.

Özyürek, A., Kita, S., Allen, S., Brown, A., Furman, R., \& Ishizuka, T. (2008).

Development of cross-linguistic variation in speech and gesture: Motion events in English and Turkish. Developmental Psychology, 44, 1040-1054.

Özyürek, A., Kita, S., Allen, S., Furman, R., \& Brown, A. (2005). How does linguistic framing of events influence co-speech gestures?: Insights from crosslinguistic variations and similarities. Gesture, 5, 219-240.

Papafragou, A., Massey, C. \& Gleitman, L. (2002). Shake, rattle, 'n' roll: The representation of motion in language and cognition. Cognition, 84, 189-219.

Papafragou, A., Massey, C. \& Gleitman, L. (2006) When English proposes what Greek presupposes: The cross-linguistic encoding of motion events. Cognition, 98, B75-B87. 
Paradis, J. \& Genesee, F. (1996). Syntactic acquisition in bilingual children: Autonomous or interdependent? Studies in Second Language Acquisition, 18, 1-25.

Paradis, J. \& Navarro, S. (2003). Subject realization and crosslinguistic interference in the bilingual acquisition of Spanish and English: What is the role of the input? Journal of Child Language, 30, 371-393.

Paradis, J. \& Nicoladis, E. (2007). The influence of dominance and sociolinguistic context on bilingual preschoolers' language choice. The International Journal of Bilingual Education and Bilingualism, 10, 277-297.

Pavlenko, A. (2009). Conceptual representation in the bilingual lexicon and second language vocabulary learning. In A. Pavlenko (Ed.), The bilingual mental lexicon: Interdisciplinary approaches (pp. 125-160). Bristol: Multilingual Matters.

Slobin, D. I. (1996a). From 'thought and language' to 'thinking for speaking'. In J. J. Gumperz \& S. C. Levinson (Eds.), Rethinking linguistic relativity (pp. 70-96). Cambridge: Cambridge University Press.

Slobin, D. I. (1996b) Two ways to travel: Verbs of motion in English and Spanish. In M. Shibatani \& S. A. Thompson (eds.), Grammatical Constructions: Their Form and Meaning (pp. 195-219). Oxford: Oxford University Press.

Slobin, D. I, (1987). Thinking for speaking. In J. Aske, N. Beery, L. Michaelis, \& H. Filip (Eds.), Proceedings of the 13th annual meeting of the Berkeley Linguistic Society (pp. 435-445). Berkeley: Berkeley Linguistic Society.

Smithson, L., Paradis, J., \& Nicoladis, E. (2014). Bilingualism and vocabulary achievement: Could socio-cultural context make a difference? Bilingualism: 
Language and Cognition. FirstView Article / July 2014, pp 1 - 12 DOI:

10.1017/S1366728913000813, Published online: 04 March 2014

Soroli, E., Sahraoui, H., \& Sacchet, C. (2012). Linguistic encoding of motion events in English and French : Typological constraints on second language acquisition and agrammatic aphasia. Language, Interaction and Acquisition, 3, 261-287.

Stam, G. (2006). Thinking for speaking about motion: L1 and L2 speech and gesture. IRAL, 44, 145-171.

Talmy, L. (2000). Toward a Cognitive Semantics. Volume II: Typology and process in concept structuring. Cambridge, Mass.: The MIT Press.

Talmy, L. (1991). Path to realization: A typology of event conflation. Proceedings of the Seventeenth Annual Meeting of the Berkeley Linguistics Society, 480-519. Berkeley, CA: Berkeley Linguistics Society.

Talmy, L. (1985). Lexicalization patterns: Semantic structure in lexical forms. In T. Shopen (Ed.), Language Typology and Syntactic Description (pp. 57-149). Cambridge: Cambridge University Press. 


\section{Appendix 1}

Verbs Classified as Path or Manner in English and French

\begin{tabular}{|c|c|c|c|}
\hline \multicolumn{2}{|l|}{ English } & \multicolumn{2}{|l|}{ French } \\
\hline Path & Manner & Path & Manner \\
\hline Chase & Boat & Aller & Courir \\
\hline Come & Climb & Arriver & Conduire \\
\hline Do loops & Crash & Aterrir & Glisser \\
\hline Follow & Do flips & Avancer & Marcher \\
\hline Go & Dive & Couler & Nager \\
\hline Get out/back/in/of & Do like a bird & Débarquer & Pédaler \\
\hline Head & Fall & Descendre & Plonger \\
\hline Land & Fly & Décoller & Promener \\
\hline Move & Go zooming & Ejecter & Recourir \\
\hline Pass & Hop & Embarquer & Retomber \\
\hline Reverse & Jump & Entrer & Rouler \\
\hline Sink & Paddle & Lever & Sauter \\
\hline Take off & Ride & Monter & Tomber \\
\hline \multirow[t]{8}{*}{ Turn } & Roll & Partir & Tourner \\
\hline & Row & Passer & Voler \\
\hline & Run & Re-aller & \\
\hline & Sail & Reculer & \\
\hline & Skedaddle & Redescendre & \\
\hline & Slow & Remonter & \\
\hline & Swim & Rendre & \\
\hline & Swirl & Rentrer & \\
\hline
\end{tabular}




\begin{tabular}{|l|l|l|l|}
\hline Wake a walk & Repartir & \\
& Repasser & Resortir \\
& Retourner & \\
& Revenir & \\
& S'enfuir & \\
& Sortir & \\
& Suivre & \\
& Venir & \\
\end{tabular}




\section{Appendix 2}

\section{Average (SD) Numbers of Motion Encodings}

\begin{tabular}{|c|c|c|c|c|c|}
\hline & & $\begin{array}{l}\text { Monolingual } \\
\text { French }\end{array}$ & $\begin{array}{l}\text { Bilingual } \\
\text { (French) }\end{array}$ & $\begin{array}{l}\text { Bilingual } \\
\text { (English) }\end{array}$ & $\begin{array}{l}\text { Monolingual } \\
\text { English }\end{array}$ \\
\hline \multicolumn{6}{|c|}{ Motion lexicalizations token } \\
\hline & Younger & $12.8(5.8)$ & $10.9(8.5)$ & $9.3(6.4)$ & $7.5(3.0)$ \\
\hline & Older & $17.0(11.0)$ & $18.1(3.4)$ & $17.8(7.7)$ & $13.7(7.8)$ \\
\hline & All & $15.1(9.1)$ & $15.2(6.8)$ & $14.4(8.3)$ & $10.9(6.8)$ \\
\hline \multicolumn{6}{|c|}{ Motion lexicalizations type } \\
\hline & Younger & $8.1(3.1)$ & $5.5(3.3)$ & $4.9(2.7)$ & $4.7(1.3)$ \\
\hline & Older & $9.8(4.8)$ & $9.3(2.3)$ & $6.8(2.1)$ & $6.4(2.8)$ \\
\hline & All & $9.1(4.1)$ & $7.8(3.3)$ & $6.0(2.5)$ & $7.8(3.0)$ \\
\hline \multicolumn{6}{|l|}{ Motion gestures } \\
\hline & Younger & $3.8(4.6)$ & $1.5(2.5)$ & $2.4(2.6)$ & $2.1(2.1)$ \\
\hline & Older & $6.0(6.7)$ & $7.3(5.3)$ & $5.3(6.1)$ & $4.2(5.0)$ \\
\hline & All & $5.0(5.8)$ & $5.0(5.2)$ & $4.1(5.1)$ & $3.2(5.0)$ \\
\hline
\end{tabular}


Table 1. Background characteristics of participants

\begin{tabular}{|c|c|c|c|c|}
\hline & & $\begin{array}{l}\text { Monolingual } \\
\text { French }\end{array}$ & $\begin{array}{l}\text { French-English } \\
\text { Bilingual }\end{array}$ & $\begin{array}{l}\text { Monolingual } \\
\text { English }\end{array}$ \\
\hline \multicolumn{5}{|l|}{ Younger } \\
\hline & $\mathrm{N}$ & 10 & 8 & 10 \\
\hline & $\begin{array}{l}\text { Average }(\mathrm{SD}) \text { age } \\
\text { in years }\end{array}$ & $6.0(0.1)$ & $5.4(0.5)$ & $5.9(0.2)$ \\
\hline & \# Girls/ Boys & $7 / 3$ & $3 / 5$ & $4 / 6$ \\
\hline \multicolumn{5}{|l|}{ Older } \\
\hline & $\mathrm{N}$ & 12 & 12 & 12 \\
\hline & $\begin{array}{l}\text { Average (SD) age } \\
\text { in years }\end{array}$ & $8.8(0.5)$ & $8.9(0.7)$ & $8.8(0.9)$ \\
\hline & \# Girls/ Boys & $7 / 5$ & $6 / 6$ & $9 / 3$ \\
\hline
\end{tabular}


Table 2. Example coding

\begin{tabular}{|l|l|l|l|}
\hline & Path & Manner & Path/Manner \\
\hline English & He passed by. & He was flying. & He flew around. \\
\hline French & Il s'est passé. & Il volait. & Il a volé autour. \\
\hline
\end{tabular}


Table 3. Average (SD) numbers of motion events lexicalized in speech or encoded in gesture

\begin{tabular}{|c|c|c|c|c|c|}
\hline & & $\begin{array}{l}\text { Monolingual } \\
\text { French }\end{array}$ & $\begin{array}{l}\text { Bilingual } \\
\text { (French) }\end{array}$ & $\begin{array}{l}\text { Bilingual } \\
\text { (English) }\end{array}$ & $\begin{array}{l}\text { Monolingual } \\
\text { English }\end{array}$ \\
\hline \multicolumn{6}{|l|}{ Word Types } \\
\hline & Younger & $112.8(23.9)$ & $96.1(35.8)$ & $95.6(29.6)$ & $67.3(23.1)$ \\
\hline & Older & $127.8(38.5)$ & $155.8(32.4)$ & $148.1(40.2)$ & $150.5(44.2)$ \\
\hline & All & $121.0(31.9)$ & $131.9(44.5)$ & $127.1(44.2)$ & $112.7(55.2)$ \\
\hline \multicolumn{6}{|c|}{ Speech \%Path (out of Total Motion types) } \\
\hline & Younger & $64.2(13.5)$ & $46.8(21.9)$ & $41.9(29.7)$ & $35.5(16.9)$ \\
\hline & Older & $61.5(30.4)$ & $61.5(10.1)$ & $47.1(16.4)$ & $40.8(11.5)$ \\
\hline & All & $60.7(24.8)$ & $55.7(17.0)$ & $45.0(22.1)$ & $38.4(14.1)$ \\
\hline \multicolumn{6}{|c|}{ Speech \%Path (out of Total Motion tokens) } \\
\hline & Younger & $68.7(11.8)$ & $49.9(23.1)$ & $56.8(23.3)$ & $45.8(21.3)$ \\
\hline & Older & $58.3(31.5)$ & $70.6(8.6)$ & $72.9(14.2)$ & $50.5(13.9)$ \\
\hline & All & $63.1(24.6)$ & $62.4(18.6)$ & $66.5(20.0)$ & $48.4(17.4)$ \\
\hline \multicolumn{6}{|c|}{ Speech \%Manner-only (out of Manner $+\mathrm{M} / \mathrm{P}$ ) } \\
\hline & Younger & $76.3(25.5)$ & $71.2(31.0)$ & $63.9(25.5)$ & $55.3(29.4)$ \\
\hline & Older & $59.3(34.8)$ & $63.5(15.7)$ & $50.9(30.9)$ & $34.3(15.7)$ \\
\hline & All & $67.0(31.5)$ & $66.6(22.6)$ & $55.7(30.3)$ & $43.8(24.8)$ \\
\hline
\end{tabular}


Table 4. Averages (SDs) for the Dependent Variables Related to Gesture Use

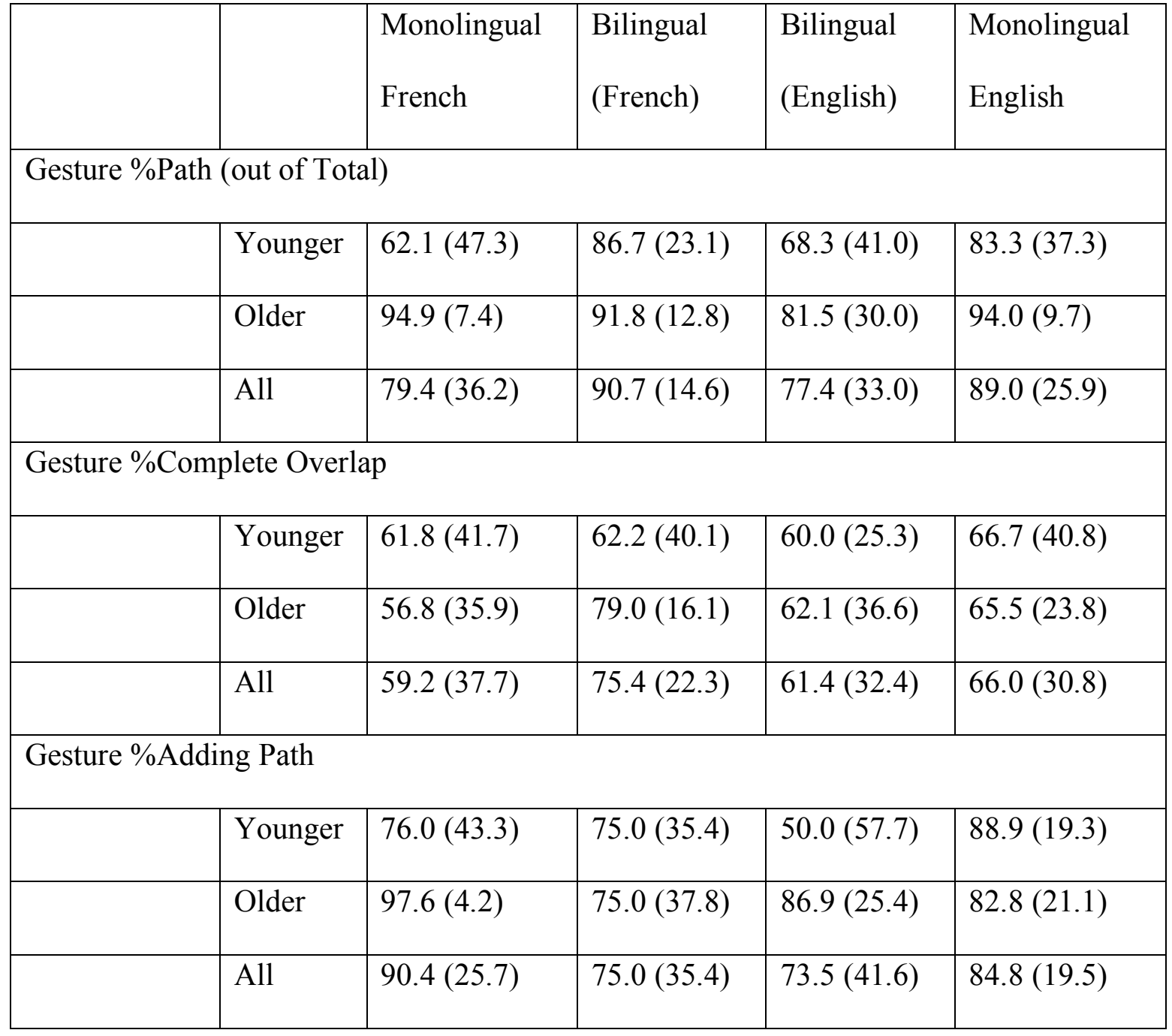

